\title{
Qualidade microbiológica e caracterização da resistência antimicrobiana de bactérias isoladas de queijos Coalho comercializados em Vitória da Conquista-
} Bahia

\author{
Adriele Pinheiro Bomfim ${ }^{1}$, Daniel Bomfim Costa ${ }^{2}$, Igor Matheus de Novais Silva ${ }^{2}$, Ivo Cesar \\ Santos Araújo ${ }^{2}$, Raíssa Aragão Andrade ${ }^{2}$, Rebeca Soares Galvão², Vanessa Vieira Cerqueira², Joice \\ Neves Reis ${ }^{3}$, Milena Soares dos Santos ${ }^{4}$
}

Neste estudo foram determinadas a qualidade higiênico-sanitária, a prevalência e a resistência antimicrobiana de patógenos isolados de 24 amostras de queijo Coalho comercializados em duas feiras livres do município de Vitória da Conquista, Bahia. Foram realizadas análises físico-químicas e microbiológicas através de métodos convencionais interpretados conforme legislação vigente. Identificamos que $75 \%$ das amostras eram comercializadas em temperatura inadequada e que 100\% apresentaram contagem para coliformes totais acima do limite aceitável. Staphylococcus coagulase positiva e Escherichia coli foram isolados em 87,5\% e 62,5\% das amostras, respectivamente. Não foi detectada a presença de Listeria monocytogenes e Salmonella sp. Identificamos 51,1\% de resistência a pelo menos um dos sete antimicrobianos testados para Staphylococcus coagulase positiva e 44,4\% para pelo menos um dos 11 avaliados para E.coli. As análises realizadas evidenciaram uma precariedade higiênicosanitária na produção e comercialização de queijo coalho nas feiras livres de Vitória da Conquista. Torna-se também uma preocupação, a presença de bactérias resistentes aos antimicrobianos nestes queijos. Deste modo, ressaltamos a importância do controle de qualidade na produção e comercialização destes produtos, assim como a necessidade das ações da vigilância sanitária para orientação aos manipuladores e produtores de queijo.

Palavras-chave: Indicadores microbiológicos, produtos lácteos, inocuidade alimentar.

\section{Microbiological quality and antimicrobial resistance characterization of bacteria in "Coalho" cheese commercialized in Vitória da Conquista-Bahia}

In this study, the hygienic and sanitary quality, prevalence, and antimicrobial resistance of pathogens isolated from 24 samples of "Coalho" cheese marketed in two street markets of the municipality of Vitória da Conquista, Bahia, were assessed. Physicochemical and microbiological analyses were performed using conventional methods according to the current legislation. A total of $75 \%$ of the samples were commercially packaged at an inadequate temperature, and all had total coliform count above the acceptable limit. Coagulase-positive Staphylococcus and Escherichia coli were isolated from $87.5 \%$ and $62.5 \%$ of the samples, respectively. The presence of Listeria monocytogenes and Salmonella sp was not detected. More than half of the coagulase-positive Staphylococcus (51.1\%), and $44.4 \%$ of the E.coli displayed resistance to at least one of the seven and 11 antimicrobials tested, respectively. The analyses revealed poor sanitary and hygienic conditions in the production and marketing of

\footnotetext{
${ }^{1}$ Mestranda do Curso de Pós Graduação em Ciências Farmacêuticas, Faculdade de Farmácia, Universidade Federal da Bahia.

${ }^{2}$ Graduando(a) do Curso de Farmácia, Instituto Multidisciplinar em Saúde, Campus Anísio Teixeira, Universidade Federal da Bahia

${ }^{3}$ Professora Associada, Curso de Pós Graduação em Ciências Farmacêuticas, Faculdade de Farmácia, Universidade Federal da Bahia.

${ }^{4}$ Professora Adjunta, Instituto Multidisciplinar em Saúde, Campus Anísio Teixeira, Universidade Federal da Bahia. Endereço para Correspondência: Instituto Multidisciplinar em Saúde, Campus Anísio Teixeira, Universidade Federal da Bahia. Rua Hormindo Barros, n58,Qd 17, Lt 58. Candeias. Vitória da Conquista, Bahia, Brasil. CEP: 45029-094. E-mail: milenasoares.ims@gmail.com
} 
curd cheese at the street markets of Vitória da Conquista. The presence of antimicrobial-resistant bacteria in these cheeses is also a concern. Therefore, we emphasize the importance of quality control in the production and marketing of these products, as well as the need for health surveillance to guide cheese handlers and producers.

Keywords: Microbiological Indicators, dairy products, food safety.

\section{INTRODUÇÃO}

As doenças transmitidas por alimentos têm sido reportadas mundialmente e constituem um problema para a saúde pública. Estimativas sugerem que nos Estados Unidos, 48 milhões de pessoas adoecem devido ao consumo de alimentos contaminados por algum tipo de patógeno, sendo hospitalizadas um total de 128.000 e destas, um total de 3.000 chegam a óbito[1,2,3]. A contaminação microbiana desses produtos geralmente envolvem falhas na cadeia de produção, desde a obtenção da matéria prima até o produto final chegar ao consumidor. Além do risco de causar surtos para a população, há também a possibilidade de prejuízos econômicos para os produtores ${ }^{[4,5,6]}$.

A segurança nutricional e dos alimentos tem como base práticas alimentares promotoras de saúde, sustentada em três pilares: acesso regular e permanente, quantidade suficiente e qualidade biológica, sanitária e nutricional[7]. Entre os alimentos mais frequentes da dieta da população, o queijo destaca-se entre os derivados láticos pelo alto teor de proteína, aminoácidos essenciais, minerais e gorduras $^{[8,9]}$.

Mesmo com o desenvolvimento tecnológico para a produção de queijos, surgiram a nível nacional muitas variedades, algumas de expressão regional, cuja maior produção ocorre de modo artesanal, sendo comumente elaborado a partir do leite cru (não pasteurizado). Embora sejam mantidas as características tradicionais, este leite pode ser caracterizado como uma importante fonte de bactérias potencialmente prejudiciais aos seres humanos $[2,8,9]$.

Segundo a Instrução Normativa n ${ }^{\circ} 30$ de 26 de junho de 2001 do Ministério da Agricultura, Pecuária e Abastecimento (MAPA), o queijo de Coalho é obtido através da coagulação do leite por meio do coalho ou outras enzimas coagulantes apropriadas, complementada ou não pela ação de bactérias lácteas selecionadas e comercializado normalmente com até dez dias de fabricação[5]. A produção dos queijos artesanais muitas vezes ocorre sem seguir a legislação vigente e as Boas Práticas de Fabricação (BPF), sendo comercializados, na maioria das vezes, de maneira informal[5,9].

Ainda que o queijo seja considerado um alimento saudável e nutritivo, as doenças transmitidas por alimentos (DTAs) estão associadas ao seu consumo em muitos países. Listeria monocytogenes, Salmonella sp, Staphylococcus aureus e Escherichia coli são os principais patógenos encontrados como fonte de contaminação deste produto $[4,10,11]$.

A avaliação de higiene e segurança dos alimentos é feita através da detecção de alguns microrganismos considerados como indicadores (coliformes) ou patogênicos. A presença de microrganismos indicadores em alimentos nos fornece informações sobre a ocorrência de contaminação de origem intestinal, sendo usualmente utilizado como agente indicador a bactéria E.coli e dentre os patogênicos, pode-se destacar Salmonella spp., Staphylococcus aureus e Listeria spp. que podem estar relacionados com o estado de portador do manipulador ${ }^{[6,11]}$.

Considerando a importância epidemiológica que representa a identificação de patógenos causadores de processos infecciosos no homem, em termos de clínica e terapêutica, o perfil de susceptibilidade aos antimicrobianos assume papel relevante para as opções terapêuticas e para a saúde humana. Esta é uma situação de interesse global considerando que na produção animal são utilizadas drogas antimicrobianas que exercem pressão seletiva sobre os microrganismos e ao consumir alimentos de origem animal ou vegetal, podem-se contrair microrganismos resistentes reduzindo as opções terapêuticas e podendo dificultar o tratamento[12,13].

Quando se trata do estabelecimento e da manutenção de doenças na população, a emergência da resistência aos antibióticos é um fator preocupante. Bactérias multirresistentes a drogas isoladas de humanos são geralmente clones dispersos no ambiente, em animais e vegetais que carreiam genes para resistência aos principais 
Microbiologia e resistência antibacteriana em queijo Coalho. Bomfim et al.

antibióticos de uso clínico. A utilização dos antimicrobianos gerou grande otimismo em relação à prevenção e ao tratamento dos processos infecciosos, entretanto, o uso exagerado e nem sempre criterioso e racional dos antibióticos e quimioterápicos trouxe problemas à Saúde Pública, sendo o maior deles representado pela progressiva resistência bacteriana às drogas ${ }^{[14,15]}$.

Houve mudanças no perfil epidemiológico de DTAs devido à expansão dos mercados de consumo, a globalização econômica, alterações dos hábitos alimentares e aumento no consumo de alimentos industrializados ou produzidos fora do lar; porém, DTAs continuam sendo uma das principais causas de morbidade nos países da América Latina e Caribe. No Brasil, as doenças infecciosas, parasitárias e do aparelho digestivo corresponderam a $9,2 \%$ do total de casos de mortalidade, sendo as regiões do Norte e Nordeste brasileiro as mais afetadas ${ }^{[16]}$. Desta maneira, a avaliação da segurança dos alimentos pode se constituir como um alerta para os consumidores e para órgãos responsáveis pela saúde pública, uma vez que produtos disponíveis para comercialização podem representar um risco à saúde, se não forem seguidos, com rigor, cuidados higiênico-sanitários durante o processo de produção ${ }^{[13]}$.

A Bahia é um dos maiores estados produtores de queijo artesanal do Nordeste ${ }^{[1]}$. Estudos prévios realizados no município de Vitória da Conquista detectaram elevada frequência de microrganismos em produtos lácteos, sugerindo que alimentos com potencial contaminação por microrganismos patogênicos são frequentemente comercializados ${ }^{[17,18]}$. Deste modo, este trabalho teve como objetivos avaliar as condições higiênicosanitárias de amostras de queijo Coalho comercializadas em feiras livres no município de Vitória da Conquista, Bahia e investigar a prevalência de agentes patogênicos e o perfil de susceptibilidade aos antimicrobianos.

\section{MATERIAL E MÉTODOS}

\section{Delineamento Experimental}

Trata-se de uma pesquisa de caráter descritivo realizado em 15 pontos de venda de produtos lácteos de duas feiras livres de maior circulação de consumidores no município de Vitória da Conquista, situado na região sudoeste do estado
Bahia, a $509 \mathrm{~km}$ da capital, cuja população registrada no último censo foi de 306.866 habitantes (IBGE) ${ }^{[19]}$. O estudo foi conduzido no período de fevereiro a abril de 2017.

Um total de 24 amostras foi adquirido em duas feiras livres nos pontos de venda $\mathrm{A}$ e $\mathrm{B}$, que comercializavam a quantidade mínima de $100 \mathrm{~g}$, das quais 20 amostras no ponto A e quatro no ponto B. Foram incluídos no estudo somente aqueles oriundos de produção artesanal informal (sem registro de inspeção municipal, estadual e/ou federal) e que não apresentaram alterações em suas características macroscópicas e organolépticas. Os produtos que não se enquadravam nestas condições, foram excluídos da avaliação.

\section{Transporte de amostras}

As amostras foram acondicionadas em caixas isotérmicas contendo gelo reciclável e termômetro para controle de temperatura, e transportadas para o Laboratório de Microbiologia de Alimentos da Universidade Federal da Bahia, Instituto Multidisciplinar em Saúde, Campus Anísio Teixeira.

\section{Análises físico-químicas}

A temperatura das amostras foi aferida no momento da coleta, com auxílio de um termômetro químico com escala interna de $0^{\circ} \mathrm{C}$ a $110^{\circ} \mathrm{C}$. Para determinação do índice de acidez foram utilizados $10 \mathrm{~g}$ da amostra em $100 \mathrm{~mL}$ de água livre de $\mathrm{CO}_{2}$ a $40^{\circ} \mathrm{C}$. Em uma alíquota de 50 $\mathrm{mL}$, foram adicionadas algumas gotas de solução alcoólica de fenolftaleína $1 \%$ e foi realizada titulação com solução $\mathrm{NaOH}$ 0,1 M com o auxílio do acidímetro até a mudança de coloração. $\mathrm{O}$ valor da acidez titulável foi utilizado para calcular o teor de ácido lático expresso em porcentagem (\%).

\section{Análise microbiológica e criopreservação bacteriana}

Foram utilizados os métodos conforme preconizado pela FDA (Food and Drug Association) e adaptado por Silva et al.[22]: As amostras foram preparadas utilizando-se $25 \mathrm{~g}$ em $225 \mathrm{~mL}$ de água peptonada, homogeneizadas e submetidas às diluições seriadas $10^{-1}, 10^{-2}$ e $10^{-3}$. Coliformes totais e termotolerantes foram determinados através da técnica de tubos múltiplos utilizando-se o caldo Lauril 
Microbiologia e resistência antibacteriana em queijo Coalho. Bomfim et al.

Sulfato Triptose com incubação a $35^{\circ} \mathrm{C}$ por $24-48 \mathrm{~h}$. As amostras positivas foram inoculadas em Caldo E.coli e Verde Brilhante 2\% (Himedia ${ }^{\circledR}$ ), interpretadas conforme número mais provável/grama (NMP/g) e semeadas em ágar eosina azul de metileno (Himediaß). As colônias suspeitas de E.coli foram submetidas aos testes de identificação bioquímica convencionais. A identificação e contagem de Staphylococcus foi realizada através deágar Baird-Parker (Beckton-Dickinson, Difco ${ }^{\circledR)}$ conforme diluições 10 $1,10^{-2}$ e $10^{-3}$. As colônias suspeitas foram submetidas à coloração de Gram, testes de catalase e coagulase em lâmina. Os resultados foram expressos em (UFC/g-1). Para pesquisa de Salmonella sp as amostras foram préenriquecidas em caldo Rappaport-Vassiliadis-Soja a $41,5^{\circ} \mathrm{C}$ por $24 \mathrm{~h}+/-3 \mathrm{~h}$ e posteriormente semeadas em meios seletivos ágar Hecktoen e Xilose-LisinaDesoxicolato (Himediaß) sob incubação $37^{\circ} \mathrm{C}+/-$ $1^{\circ} \mathrm{C} / 24 \mathrm{~h}+/-3 \mathrm{~h}$. Colônias suspeitas foram submetidas aos testes convencionais bioquímicos. Para identificação de L. monocytogenes as amostras foram pré-enriquecidas em caldo de enriquecimento tamponado (BLEB, Beckton-Dickinson, Difco $\left.{ }^{\circledR}\right)$ incubados a $30^{\circ} \mathrm{C} / 4 \mathrm{~h}$, posteriormente suplementado com antimicrobianos, semeadas em meio seletivo ágar PALCAM com antimicrobianos e reincubados a $35^{\circ} \mathrm{C} / 24-48 \mathrm{~h}$. Os microrganismos isolados foram armazenados em caldo Brain Heart Infusion (Himedia ${ }^{\circledR}$ ) acrescido de glicerol 10\% em freezer $20^{\circ} \mathrm{C}$ até o momento de realização do teste de susceptibilidade antimicrobiana.

\section{Caracterização do perfil de susceptibilidade antimicrobiana}

As bactérias criopreservadas foram semeadas em meio de cultivo TSA (Trypticase Soy Agar, Himedia $\left.{ }^{\circledR}\right)$ utilizando-se a técnica do esgotamento, e incubadas a $35^{\circ} \mathrm{C}$ por 24 horas. Após este período, foi realizada reativação utilizando-se o mesmo meio de cultivo para obtenção de colônias isoladas. O perfil de susceptibilidade antimicrobiana foi determinado através do método de disco-difusão utilizando-se ágar Mueller-Hinton (Becton Dickinson, Alemanha ${ }^{\circledR}$ ) e discos de antibióticos (Sensifar( $\left.{ }^{\circledR}\right)$. Os isolados de Staphylococcus coagulase positiva foram testados para os antibióticos cefoxitina, gentamicina, cloranfenicol, tetraciclina, sulfametoxazol/trimetoprim, eritromicina, clindamicina e foram submetidos ao $D$-teste para detectar resistência induzível à clindamicina. Os isolados de E.coli foram testados para os antibióticos cefoxitina, azitromicina, gentamicina, cloranfenicol, tetraciclina, sulfametoxazol/trimetoprim e meropenem. A presença de cepas ESBL (Betalactamase de Espectro Estendido) foi investigada através do teste de aproximação de discos de amoxicilina associado ao ácido clavulânico, aztreonam, ceftriaxona e ceftazidima. $O$ teste de Hodge modificado foi utilizado para avaliar presença de cepas produtoras de carbapenemase (KPC). As cepas S.aureus ATCC 25923 e E.coli ATCC 25922 foram utilizadas como controle de qualidade. As amostras testadas foram classificadas como resistente, intermediária ou sensível em função do diâmetro da zona de sensibilidade e interpretados conforme recomendações do Clinical and Laboratory Standards Institute (CLSI, 2017) ${ }^{[23] .}$

\section{Análise dos dados}

Os dados foram analisados com o programa Excel (Windows, 2010) através de estatística descritiva e quantitativa utilizando-se medidas de dispersão e frequência simples. Os resultados foram interpretados de acordo com os critérios da Resolução da Diretoria Colegiada 12, de 2001 da ANVISA[20].

\section{RESULTADOS}

Do total de amostras coletadas no presente estudo, $75 \%$ estavam sendo comercializadas em temperatura fora da faixa aceitável conforme instrução MAPA $\left(10^{\circ} \mathrm{C} \text { a } 12^{\circ} \mathrm{C}\right)^{[21]}$, cuja média foi de $14,87^{\circ} \mathrm{C}$. Parâmetros físico-químicos das amostras podem ser observados na Tabela 1. 
Microbiologia e resistência antibacteriana em queijo Coalho. Bomfim et al.

Tabela 1. Análise físico-química de amostra de queijos Coalho obtidas em feiras livre de Vitória da Conquista, Bahia

\begin{tabular}{cccc}
\hline $\begin{array}{c}\text { Parâmetros } \\
\text { Físico } \\
\text { Químicos }\end{array}$ & Resultados & $\begin{array}{c}\text { *No de } \\
\text { Amostras }\end{array}$ & \% \\
\hline $\begin{array}{c}\text { Temperatura de } \\
\text { Comercialização } \\
\left({ }^{\circ} \mathrm{C}\right)\end{array}$ & 10 a 12 & 6 & 29,2 \\
& $>12$ & 11 & 45,8 \\
\hline & 0,02 a 0,04 & 9 & 37,5 \\
Acidez $(\%)$ & 0,05 a 0,07 & 12 & 50,0 \\
0,08 a 0,10 & 3 & 12,5 \\
\hline *No = Número & & &
\end{tabular}

Fonte: Os autores.
A qualidade microbiológica foi avaliada através da identificação de microrganismos indicadores e patogênicos (Tabela 2). Todas as amostras avaliadas apresentaram coliformes totais, com contagem $>1.100 \mathrm{NMP} / \mathrm{g}$, das quais $62,5 \%$ foram positivas para a pesquisa de coliformes termotolerantes com a confirmação de Escherichia coli e contagens variando entre 240 a $>1100$ $\mathrm{NMP} / \mathrm{g}$. Staphylococcus coagulase positiva foi detectado em 91,66\% das amostras de queijo de Coalho, das quais $87,5 \%$ apresentaram contagem acima do limite permitido pela legislação $\left(5 \times 10^{2}\right.$ $\mathrm{UFC} / \mathrm{g})$. Não foram detectadas a presença dos agentes patogênicos Salmonella sp e L. monocytogenes nas amostras analisadas.

Tabela 2. Avaliação microbiológica de queijo Coalho comercializado em feiras livres em Vitória da Conquista Bahia

\begin{tabular}{|c|c|c|c|}
\hline Microrganismos & Contagens & $* \mathbf{N} \mathbf{o}$ & Frequência (\%) \\
\hline Coliformes totais (NMP/g**) & $>1.100$ & 24 & 100 \\
\hline \multirow{2}{*}{$\begin{array}{l}\text { Coliformes termotolerantes } \\
\text { (NMP/g) }\end{array}$} & $>1.100$ & 13 & 54,16 \\
\hline & 240 & 2 & 8,33 \\
\hline \multirow{2}{*}{$\begin{array}{c}\text { Staphylococcus coagulase positiva } \\
\left.\text { (UFC } / \mathrm{g}^{* * *}\right)\end{array}$} & $<10^{3}$ & 1 & 4,17 \\
\hline & $>10^{3}$ & 21 & 87,50 \\
\hline \multirow{2}{*}{$\begin{array}{l}\text { L. monocytogenes } \\
\text { (Em } 25 \mathrm{~g})\end{array}$} & Ausência & 24 & 100 \\
\hline & Presença & 0 & 0 \\
\hline Salmonella sp. & Ausência & 24 & 100 \\
\hline (Em $25 \mathrm{~g})$ & Presença & 0 & 0 \\
\hline Total de amostras & & 24 & \\
\hline
\end{tabular}

$*$ No=Número de amostras

**NMP/g:Número Mais Provável/grama

***UFC/g:Unidade Formadora de Colônia/grama

Fonte: Os autores.

Os isolados de Staphylococcus coagulase positiva e E.coli foram submetidos ao teste de susceptibilidade antimicrobiana. Das 22 cepas de Staphylococcus coagulase positiva identificadas, 17 estavam aptas para o teste. Destas, 52,9\% apresentaram resistência a pelo menos um antimicrobiano e cinco apresentaram sensibilidade a todos os antimicrobianos testados. A resistência foi identificada para: oxacilina e gentamicina $(23,5 \%$ cada), eritromicina $(17,6 \%)$ e tetraciclina $(5,9 \%$; ) e padrão de resistência intermediária para: clindamicina (11,8\%), eritromicina, sulfametoxazol/trimetoprim e gentamicina (5,9\%). Nenhum isolado apresentou resistência ao cloranfenicol (Tabela 3) 
Tabela 3. Perfil de suscetibilidade antimicrobiana de Staphylococcus coagulase positiva oriundos de amostras de queijo Coalho coletadas em feiras livres de Vitória da Conquista - Bahia.

\begin{tabular}{ccccccc}
\hline \multirow{2}{*}{ Antimicrobianos } & \multicolumn{2}{c}{ Sensível } & \multicolumn{2}{c}{ Intermediário } & \multicolumn{2}{c}{ Resistente } \\
\cline { 2 - 7 } & *No & $\mathbf{( \% )}$ & $\mathbf{N}$ o & $\mathbf{( \% )}$ & No & $\mathbf{( \% )}$ \\
\hline Oxacilina & 13 & 76,5 & 0 & 0 & 4 & 23,5 \\
Clindamicina & 15 & 88,2 & 2 & 11,8 & 2 & 0 \\
Cloranfenicol & 17 & 100 & 0 & 0 & 0 & 0 \\
Eritromicina & 14 & 76,5 & 1 & 5,9 & 3 & 17,6 \\
Sulfametoxazol/ & 16 & 94,1 & 1 & 5,9 & 0 & 0 \\
Trimetoprim & & & & & & \\
Gentamicina & 13 & 70,6 & 1 & 5,9 & 4 & 23,5 \\
Tetraciclina & 16 & 94,1 & 0 & 0 & 1 & 5,9 \\
\hline
\end{tabular}

$* \mathrm{~N}$ o $=$ Número de isolados

Fonte: Os autores.

Entre as 15 amostras positivas para E.coli, foi possível realizar o teste para 9 cepas. Destas, $44,4 \%$ foram resistentes a pelo menos um antimicrobiano e 5 foram sensíveis a todos os antimicrobianos testados. Foi determinada resistência para os seguintes antimicrobianos: tetraciclina (33,3\%), azitromicina $(22,2 \%)$, amicacina, amoxicilina associada ao ácido clavulânico e sulfametoxazol/trimetoprim apresentaram resistência em $11,1 \%$ das cepas (cada). Nenhum isolado apresentou resistência à ampicilina, ceftazidima, ceftriaxona e cloranfenicol (Tabela 4). Não foram identificados isolados com fenótipo de resistência por ESBL ou carbapenemase (Hodge modificado).

Tabela 4. Perfil de suscetibilidade antimicrobiana de Escherichia coli isolados de amostras de queijo Coalho coletadas em feiras livres de Vitória da Conquista - Bahia.

\begin{tabular}{|c|c|c|c|c|c|c|}
\hline \multirow{2}{*}{ Antimicrobianos } & \multicolumn{2}{|c|}{ Sensível } & \multicolumn{2}{|c|}{ Intermediário } & \multicolumn{2}{|c|}{ Resistente } \\
\hline & *No & $(\%)$ & № & $(\%)$ & No & $(\%)$ \\
\hline Ampicilina & 9 & 100 & 0 & 0 & 0 & 0 \\
\hline $\begin{array}{c}\text { Amoxicilina }+ \text { Ácido } \\
\text { clavulânico }\end{array}$ & 8 & 88,9 & 0 & 0 & 1 & 11,1 \\
\hline Ceftriaxona & 9 & 100 & 0 & 0 & 0 & 0 \\
\hline Ceftazidima & 9 & 100 & 0 & 0 & 0 & 0 \\
\hline Amicacina & 8 & 88,9 & 0 & 0 & 1 & 11,1 \\
\hline Azitromicina & 7 & 77,8 & 0 & 0 & 2 & 22,2 \\
\hline Cloranfenicol & 9 & 100 & 0 & 0 & 0 & 0 \\
\hline $\begin{array}{l}\text { Sulfametoxazol/ } \\
\text { Trimetoprim }\end{array}$ & 8 & 88,9 & 0 & 0 & 1 & 11,1 \\
\hline Tetraciclina & 6 & 66,7 & 0 & 0 & 3 & 33,3 \\
\hline
\end{tabular}


*№=Número de isolados

Fonte: Os autores.

\section{DISCUSSÃO}

O queijo Coalho produzido de modo artesanal e informal é comercializado em feiras livre e muitas vezes são fabricados sem seguir orientações legais e critérios de boas práticas de fabricação, não sendo possível assegurar que as devidas precauções para evitar a contaminação do produto, como critérios na obtenção da matéria prima e das técnicas de processamento sejam estabelecidas, fazendo com que acabem levando ao mercado um produto de baixa qualidade, tanto do ponto de vista higiênico sanitário, como da padronização do produto, colocando em risco à saúde do consumidor ${ }^{[9]}$.

É um alimento que necessita ser armazenado à temperatura adequada para manutenção das características organolépticas e a garantia da segurança dos alimentos, tendo em vista que alimentos perecíveis podem ser fontes de contaminação por microrganismos[6,24,25]. Cabe ressaltar que quando a faixa de temperatura de conservação dos alimentos não é respeitada são oferecidas condições como nutrientes, umidade e temperatura para crescimento e multiplicação de bactérias patogênicas, e a provável produção de toxinas que aumentam os riscos à saúde do consumidor $[11,26,27]$.

O valor de acidez titulável é utilizado como indicador de qualidade do leite e dos seus derivados como o queijo ${ }^{[28]}$. As amostras analisadas neste estudo variaram de 0,02 a $0,10 \%$ de ácido lático. $\mathrm{Na}$ legislação não há valores de referência para as análises de acidez de queijo de Coalho. Trabalhos publicados na literatura reportam resultados que apresentam ampla faixa de variação. Sousa et al.[35] avaliaram queijos de produção industrial e sem inspeção de seis estados da região Nordeste do Brasil e identificaram acidez percentual que variaram entre 0,16 a $0,74 \%$ de ácido lático para os queijos com inspeção e de 0,12 a $1,01 \%$ para os queijos de produção artesanal, sem diferenças significativas entre ambos, enquanto que Freitas Filho et al. encontraram variação de 0,11 a $0,49 \%$ de ácido lático em amostras de queijo Coalho de produção artesanal no município de Jucati (PE)[36].
A acidez do queijo coalho pode sofrer influências de variações na concentração de ácido lático decorrente dos diferentes processos adotados para produção, devido ao tamanho dos grãos de coalhada cortados, da expulsão de soro da massa durante a fabricação e na fase inicial da cura, da quantidade de sal e método de salga, do tempo e temperatura dos queijos prensados e das atividades dos cultivos láticos presentes no leite ${ }^{[35,37]}$.

Todas as amostras de queijo de coalho estudadas apresentaram coliformes totais, sendo que $62,5 \% \quad(15 / 24) \quad$ continham coliformes termotolerantes, com contagem $>1.1000 \mathrm{NMP} / \mathrm{g}$, com confirmação de E. coli. Cabe destacar que todas as amostras em que foram detectadas contaminação com E. coli encontravam-se fora dos padrões preconizados em lei, que é de no máximo $5,0 \times 10^{3}$ $\mathrm{NMP} / g$. Estudos similares sobre o queijo Coalho realizados no Nordeste têm demonstrado altos níveis de coliformes totais e coliformes termotolerantes, com a identificação de $E$. coli[ [5,8,11,25].

E. coli é empregada como um indicador de qualidade microbiológica, uma vez que sua presença sugere a contaminação fecal nos alimentos. Não obstante sua presença seja altamente indesejável, sua eliminação por completo dos alimentos frescos e refrigerados é praticamente impossível, porém quando produzido, manipulado, armazenado e transportado sob condições adequadas a sua carga microbiológica encontra-se nos valores aceitáveis e de baixo rísco, em conformidade com o estipulado em lei[ $[6,25,29]$.

A identificação de Staphylococcus coagulase positiva foi observada em 91,7\% (22/24) das amostras de queijo de Coalho, sendo que apenas 4,2 $\%(1 / 24)$ das amostras encontravam-se nos padrões vigentes $\left(<10^{3} \mathrm{UFC} / \mathrm{g}\right)$. Este microrganismo faz parte da microbiota normal de mucosas e pele e pode ser transmitido aos alimentos por contato direto ou indireto através, por exemplo, da manipulação inadequada de alimentos ${ }^{[6,30]}$.

A elevada contagem desse agente microbiológico nos alimentos, é um fator importante em virtude da termoresistência associada às enterotoxinas produzidas por $S$. aureus (SEs), que pode oferecer risco à saúde do consumidor ${ }^{[11,31]}$. Estas são pirogênicas, podem induzir emese e gastroenterite. São resistentes a ácido, às proteases 
Microbiologia e resistência antibacteriana em queijo Coalho. Bomfim et al.

gastrointestinais e outras como pepsina, tripsina, quimotripsina, renina e papaína, estáveis em ampla faixa de $\mathrm{pH}$, resistentes ao calor, não sendo completamente desnaturadas pelo cozimento [22,32]. Situações que contribuem para que isto ocorra estão vinculadas às condições higiênicas deficientes e inadequadas que podem ser desde a sua produção (leite não pasteurizado), à manipulação, ao transporte e ao armazenamento[0,27,31]. Estudo conduzido por Necidová et al. (2019) reportaram que embora temperaturas de $100^{\circ} \mathrm{C}, 110^{\circ} \mathrm{C}$ e $121^{\circ}$ $\mathrm{C}$ possam inativar as SEs no leite, as principais medidas na prevenção da enterotoxicose estafilocócica são evitar a contaminação inicial do leite por S.aureus, promovendo o consumo de leite tratado termicamente e impedindo a interrupção da cadeia de frio durante a produção e processamento do leite ${ }^{[33]}$.

Neste estudo, não foi identificada a presença de L. monocytogenes nas amostras de queijo Coalho analisadas, porém outros trabalhos reportaram a presença do patógeno em amostras de queijo Coalho artesanal, comercializados nos estados do Amazonas, Ceará, Pernambuco e Rio Grande do Norte ${ }^{[4,8,28,34]}$. A não detecção do microrganismo em amostras, muitas vezes, está relacionada a fatores de estresse celular e à baixa concentração de células do patógeno[28]. É importante enfatizar que a maioria dos queijos analisados nos estudos citados apresentaram valores de acidez e temperatura de comercialização inapropriadas, não inibindo o crescimento desse agente ${ }^{[10,27,28,34]}$.

Apesar de não ter sido detectada a presença de Salmonella sp nas amostras analisadas, a ocorrência de DTAs com esta bactéria tem sido reportada. No Brasil as publicações e o acesso à prevalência desta doença são limitados, mas um estudo de revisão com informações do Paraná, relata $33,3 \%$ de casos de salmonelose envolvendo produtos de origem animal, animal e vegetal, cereal, plantas tóxicas e diversos [30]. Outros países como EUA e França, têm reportado surtos associados ao consumo de queijo "cru" e de leite de cabra, envolvendo 15 e 25 pessoas, respectivamente [10].

Este microrganismo tem sido isolado de amostras de queijo de Coalho oriundos tipicamente da região nordeste, como Pernambuco $(5,5 \%)$ e Rio Grande do Norte $(9 \%)^{[4,29]}$, onde são muito difundidos e considerados como queijos artesanais.
Estes alimentos, de origem animal, são mais susceptíveis à contaminação, uma vez que Salmonella sp pode colonizar o trato gastrointestinal dos animais e se medidas de higiene não forem rigorosamente adotadas durante o manejo e ordenha, poderá haver contaminação da matéria prima, pois os queijos artesanais são produzidos em sua maior parte com leite não pasteurizado[11,27,29].

Neste estudo foi identificada elevada taxa de resistência para os isolados de Staphylococcus coagulase positiva e E.coli. Guimarães e colaboradores (2012) ${ }^{[13]}$ também relataram E. coli resistente aos betalactâmicos, aminoglicosídeos e macrolídeos. Estes resultados corroboram a preocupação quanto à circulação de alimentos contaminados com agentes que além de potencial patogênico, também apresentam resistência aos principais antimicrobianos de uso tanto no ambiente ambulatorial quanto hospitalar.

Os resultados obtidos com os dados deste estudo foram informados aos comerciantes onde as amostras foram coletadas, através de um relato informativo e entrega de folders educativos com as Boas Práticas de Manipulação em Alimentos.

\section{CONCLUSÃO}

Os queijos de Coalho analisados obtidos das feiras livres do município de Vitória da Conquista, Bahia apresentaram condições impróprias para o consumo devido à ausência de higiene sanitária e inadequações quanto à temperatura de comercialização. A elevada taxa de contaminação e resistência antimicrobiana de microrganismos indicadores coloca em risco a segurança dos alimentos da população. Os dados deste estudo destacam a necessidade e a importância das ações de vigilância sanitária, assim como medidas educativas para os produtores e manipuladores, para evitar danos à saúde do consumidor e prevenir a transmissão de doenças relacionadas aos alimentos.

\section{REFERÊNCIAS}

[1] De Buyser ML, Dufour B, Maire M. et al. Implication of milk and milk products in food-borne diseases in France and in different industrialized countries. Int. J. Food. Microbiol. 2001; 67 (1-2):1-17.

[2] Oliver SP, Jayarao BM, Almeida RA. Foodborne Pathogens in Milk and the Dairy Farm Environment: 
Microbiologia e resistência antibacteriana em queijo Coalho. Bomfim et al.

Food Safety and Public Health Implications.2005; 2(2):115-29.

[3]Center of Diseases Control and Prevention (CDC).Foodborne Illnesses and Germs. Disponível em: https://www.cdc.gov/foodsafety/foodborne-germs.html

[4] Feitosa T, Borges MF, Nassu RT, Azevedo EHF, Muniz CR. Pesquisa de Salmonella sp., Listeria sp. e Indicadores Higiênico-Sanitários em Queijos Produzidos no Estado do Rio Grande do Norte. Food Sci. Technol. 2003; 23 (Supl): 162-165.

[5] Menezes SM. Queijo de Coalho: Tradição Cultural e Estratégia de Reprodução Social Na Região Nordeste. Rev. de Geog. (UFPE). 2011. v.28, n.1

[6] Jay JM. Microbiologia de alimentos. 6. ed. Porto Alegre, Brasil: Artmed; 2005.

[7] BRASIL. Lei no 11.346, de 15 de setembro de 2006. Cria o Sistema Nacional de Segurança Alimentar e Nutricional SISAN com vistas em assegurar o direito humano à alimentação adequada e dá outras providências. Diário Oficial da União. 2006; 18 set. Disponível http://www.planalto.gov.br/ccivil_03/_ato20042006/2006/lei/111346.html

[8] Borges MF,Feitosa T, Nassu RT, Muniz CR, Azevedo EHF, Figueiredo EAT. Micro-organismos Patogênicos e Indicadores em Queijo de Coalho Produzido no Estado do Ceará, Brasil. Boletim do Centro de Pesquisa de Processamento de Alimentos. 2003; Curitiba, v. 21, n. 1, jan./jun.

[9] Dantas, DS. Qualidade Microbiológica do Queijo de Coalho Comercializado no Município de Patos, PB [Dissertação]. PATOS; Universidade Federal de Campina Grande-UFCG; 2012.

[10] Choi K, Lee H, Lee S, Kim S, Yoon Y. Cheese Microbial Risk Assessments - A Review.Asian Australas. J. Anim. Sci.2016; fev 23; v.29, n. 3, 307-314.

[11] Forsythe SJ.Microbiologia da segurança alimentar. Ed. I. Porto Alegre, Brasil: Artmed; 2005.

[12] Antunes, Gilberto Silveira. Manual de Diagnóstico Bacteriológico. 2a ed. rev. e ampl. Porto Alegre (RS): Editora da Universidade/UFRGS; 1995.

[13] Guimaraes, AG et al. Perfil de susceptibilidade antimicrobiana de bactérias isoladas de queijos coalho.Rev. Inst. Adolfo Lutz (Impr.). 2012; v. 71, n. 2. Disponível em http://periodicos.ses.sp.bvs.br/scielo.php?script=sci_art text\&pid=S007398552012000200006\&lng $=$ pt\&nrm $=$ iso

[14] Katsunama Y, et al. Comparison of pulsed-field gel electrophoresis patterns of antimicrobial-resistant Escherichia coli and enterococci isolates from the feces of livestock and livestock farmers in Japan. J Gen Appl Microbiol.2008;54(1):39-50. Disponível em:https://www.ncbi.nlm.nih.gov/pubmed/18323680

[15] Ramchandani $\mathrm{M}$ et al. Possible animal origin of human-associated, multidrug-resistant uropathogenic Escherichia coli. Clin Infect Dis. 2005;40:251-7. Disponível em:https://www.ncbi.nlm.nih.gov/pubmed/15655743

[16] Shinohara NKS et al. Salmonella spp., importante agente patogênico veiculado em alimentos. Ciênc. Saúde Coletiva. 2008; v. 13, n. 5, 1675-1683. Disponível em:http:/ /www.scielo.br/scielo.php?script=sci_arttext\& pid $=$ S14131232008000500031\&lng=en\&nrm $=$ iso.

[17] Cavalcante JFM, Andrade NJ de, Furtado MM, Ferreira CLLF, Pinto CLO, Elard E. Processamento do queijo coalho regional empregando leite pasteurizado e cultura lática endógena. Ciênc. Tecnol. Aliment. 2007 ; 27(1): 205-214.

[18] Fonseca BCP da, Reis JN, Santos MS dos. Avaliação Microbiológica de Produtos Lácteos Comercializados na Cidade de Vitória da Conquista - Bahia. Rev. Saúde.Com. 2016; 12(2): 575-583.

[19] BRASIL. IBGE. Instituto Brasileiro de Geografia e Estatística. Estimativas populacionais para os municípios brasileiros.Disponível

https://cidades.ibge.gov.br/brasil/ba/vitoria-daconquista/panorama

[20] BRASIL.ANVISA.Agência Nacional de Vigilância Sanitária. Resolução RDC n. 12, de 2 de janeiro de 2001. Regulamento técnico sobre padrões microbiológicos para alimentos. Disponível em: http://portal.anvisa.gov.br/documents/33880/2568070/ RDC_12_2001.pdf/15ffddf6-3767-4527-bfac$740 \mathrm{a} 0400829 \mathrm{bhtm}$

[21] BRASIL. MAPA. Ministério da Agricultura, Pecuária e Abastecimento. Instrução normativa no 30 de 26 de junho de 2001 doDepartamento de Inspeção de produtos de origem animal doMinistério da Agricultura, Pecuária e Abastecimento. Aprova osRegulamentos Técnicos de Identidade e Qualidade de Manteigada Terra ou Manteiga de Garrafa; Queijo de Coalho e Queijo deManteiga. Diário Oficial da República Federativa do Brasil,Brasília, DF, 16 jul 2001. Seção I, p.13-5.Disponível em: 
Microbiologia e resistência antibacteriana em queijo Coalho. Bomfim et al.

http://www.defesa.agricultura.sp.gov.br/ www/ legislacoes / popup.php? action= view\&idleg=1039

[22] Silva N, Junqueira VCA, Silveira NFA, Taniwaki MH, Santos RFS, Gomes RAR. Manual de Métodos de Análise Microbiológica de Alimentos e Água.4. Ed. Santa Maria, RS; Livraria Varela; 2010.

[23] Clinical and Laboratory Standards Institute. Performance standards for antimicrobial disk susceptibility testing. Wayne, PA CLSI document M100, 27th ed.January 2017 Replaces M100-S26.

[24] BRASIL. Lei no 986, de 21 de outubro de 1969. Disponível em: http://www.anvisa.gov.br/anvisalegis/resol/16_78.htm

[25] Sousa AZB de, Abrantes MR, Sakamoto SM, Silva JB A da, Lima PO, Lima RN de, et al. Aspectos físicoquímicos e microbiológicos do queijo tipo coalho comercializado em estados do nordeste do Brasil. Arq. Inst. Biol.2014; v. 81, p.30-35.

[26] Praxedes PCG. Aspectos da qualidade higiênicosanitária de alimentos consumidos e comercializados na cidade de São Remo [Dissertação]. São Paulo: Universidade de São Paulo - USP; 2003.

[27] Olivieri, DA. Avaliação da qualidade microbiológica de amostras de mercado de queijo Mussarela, elaborado a partir de leite de búfala (Bubalus bubalis).[Dissertação]. Piracibaba:São Paulo: Universidade de São Paulo USP;2004.

[28] BRASIL. MAPA. Ministério da Agricultura, Pecuária e Abastecimento. Acidez titulável. Disponível em: https://www.agencia.cnptia.embrapa.br/Agencia8/AG0 1/arvore/AG01_194_21720039246.html

[29] Duarte DAM, Schuch DMT, Santos SB, Ribeiro AR, Vasconcelos AMM, Silva JVD, et al.Pesquisa de Listeria Monocytogenes e Microrganismos Indicadores Higiênico-Sanitários em Queijo de Coalho Produzido e Comercializado no Estado de Pernambuco. Arq.Inst. Biol, 2005; v.72, n.3, p.297-302.

[30] Amson GV, Haracemiv SMC, Masson ML. Levantamento de dados epidemiológicos relativos à ocorrências/ surtos de doenças transmitidas por alimentos (DTAs) no estado do Paraná Brasil, no período de 1978 a 2000. Ciênc. agrotec. 2006, nov./dez, Lavras. vol.30, n.6, p.1139-1145.

[31] Alves LMC, Amaral LA, Corrêa. MR, Sales SS. Qualidade Microbiológica do Leite Cru e de Queijo de Coalho Comercializados Informalmente na Cidade de
São Luís - MA. Pesquisa em Foco, 2009; v. 17, n.2, p. 01 13.

[32] Food and Drug Administration (FDA). Bad Bug Brook, Foodborn pathogenic microorganisms and natural toxins.2nd Edition. Capítulo de Staphylococcus aureus, p. 87-91.[Online] Disponível: https://www.fda.gov/media/83271/download

[33] Necidová L, Bursová S, Haruštiaková D, Bogdanovičová K, Lačanin I. Effect of heat treatment on activity of staphylococcal enterotoxins of type A, B, and C in milk. Journal of Dairy Science, 2019; v.102, Issue 5, p. 3924-3932.

[34] Guedes, VTM. Ocorrência de Listeria monocytogenes em queijos artesanais comercializados na cidade de Manaus [Dissertação].Manaus:Universidade Federal do Amazonas - UFAM, 2003.

[35] Sousa, AZB; Abrantes, MR; Sakamoto,SM; Silva, JBA; Lima, PA; Lima, RN; Rocha, MOC; Passos, YDB. Aspectos físico-químicos e microbiológicos do queijo tipo coalho comercializado em estados do nordeste do Brasil. Arq. Inst. Biol., São Paulo, v.81, n.1, p. 30-35, 2014

[36] Freitas Filho, JR; Souza Filho, JS; Oliveira, HB; Angelo, JHB; Bezerra, JDC. Avaliação da qualidade do queijo "coalho" artesanal fabricado em Jucati - PE . EXTENSIO: Revista Eletrônica de Extensão, v. 6, n. 8, dezembro de 2009. ISSN 1807-0221

[37] SCOTT, R. Fabricación de queso. 2 edição, Zaragoza- Espanha, 2002. 